\title{
Aripiprazole for late-life schizophrenia
}

This article was published in the following Dove Press journal:

Clinical Interventions in Aging

28 August 2010

Number of times this article has been viewed

\author{
Jeffrey Rado \\ Philip G Janicak \\ Psychiatric Clinical Research Center, \\ Rush University Medical Center, \\ Chicago, IL, USA
}

\begin{abstract}
Antipsychotics are frequently used in elderly patients to treat a variety of conditions, including schizophrenia. While extensively studied for their impact in younger populations, there is comparatively limited evidence about the effectiveness of these agents in older patients. Further complicating this situation are the high co-morbidity rates (both psychiatric and medical) in the elderly; age-related changes in pharmacokinetics leading to a heightened proclivity for adverse effects; and the potential for multiple, clinically relevant drug interactions. With this background in mind, we review diagnostic and treatment-related issues specific to elderly patients suffering from schizophrenia and other psychotic conditions, focusing on the potential role of aripiprazole.
\end{abstract}

Keywords: aripiprazole, schizophrenia, elderly, dopamine partial antagonist

\section{Introduction}

While the use of psychotropics in elderly patients is common, there is less evidence from controlled trials to guide clinicians' decision making. Further, several issues specific to this age group complicate prescribing for the elderly. These include age-related changes in pharmacokinetics; higher rates of medical and psychiatric co-morbidities; and an increased risk of adverse drug interactions given the greater need for combining both psychotropic and nonpsychotropic agents. In the context of prescribing antipsychotics, these issues are amplified by their frequent use in the elderly; as well as the absence of a Food and Drug Administration (FDA)-approved indication and an FDA-mandated box warning for all drugs in this class when used in older patients with dementia and related psychosis.

With this background in mind, we review the diagnosis of schizophrenia in the elderly and its management, including the use of aripiprazole in this population.

\section{Schizophrenia in late life}

Schizophrenia affects about $1 \%$ of the general population. Its clinical presentation consists of positive symptoms such as delusions and hallucinations; negative symptoms such as anergia, anhedonia, alogia, and flat affect; cognitive disruption; and dysphoria with depression. The disease has a damaging effect on interpersonal relationships, as well as the ability to function at work and school. Most patients develop these symptoms in late adolescence or young adulthood and follow a relapsing course throughout their lives. A return to premorbid functioning is uncommon. Chronicity of symptoms and high recurrence rates typically require ongoing antipsychotic therapy to prevent relapse and improve functioning. ${ }^{1}$
Correspondence: Jeffrey Rado

Psychiatric Clinical Research Center,

Rush University Medical Center,

2150 West Harrison Street,

Chicago, IL 606I2, USA

Tel +I 3129429296

Fax + I 3129427284

Email jeffrey_rado@rush.edu 
Schizophrenia affects $0.3 \%$ of Americans aged over 65 years. $^{2}$ The majority of patients with late life schizophrenia are those with an early-onset who are now elderly. A smaller proportion (approximately 25\%) develop late-onset symptoms after the age of 40 years. Compared with adult patients, the elderly typically respond to lower doses of antipsychotic medications. ${ }^{3}$ While negative symptoms may persist or worsen as the patient ages, positive symptoms often decrease in frequency and severity. By contrast, late-onset schizophrenia is usually characterized by paranoid delusions and auditory hallucinations with less prominent negative symptoms. ${ }^{4}$ Schizophrenia is a costly illness for all those affected, and the cost of care for those aged over 65 years is significantly higher than for younger age groups. ${ }^{5}$ In this context, higher levels of medical co-morbidities and cognitive dysfunction are thought to contribute.

\section{Management issues in elderly patients with schizophrenia}

Late-life schizophrenia is also associated with high levels of depression. ${ }^{6}$ In turn, depression is associated with poorer quality of life, compromised daily functioning and lower income. .,7 $^{6}$ Suicide rates in schizophrenia, however, tend to decrease with age. ${ }^{8}$ Anxiety is frequently associated with depression and positive symptoms, further impairing quality of life. ${ }^{9}$

Cognitive dysfunction is a prominent symptom of schizophrenia and may be exacerbated by age-related mental decline. Thus, memory, executive functioning, attention and new learning can be adversely affected. These cognitive deficits qualitatively resemble those found in younger patients. ${ }^{10,11}$ Further, the impairment in social functioning characteristic of schizophrenia continues into older age, although either improvement or deterioration is possible. ${ }^{12}$ In this context, impaired cognitive function appears to predict poorer social functioning. ${ }^{13,14}$ Thus, compared with same age nonpsychiatric controls, older patients with schizophrenia have significantly more problems with finances, transportation, forming friendships, and looking after their home. ${ }^{14,15}$ They are also less likely to live independently and more likely to live in supervised settings. ${ }^{16}$ Patients with schizophrenia have poorer coping skills and lower self-efficacy, both of which are associated with high levels of psychopathology. ${ }^{17}$ Improvement in coping, however, may occur as these patients age. In this context, acceptance and redirecting attention away from unwanted thoughts or symptoms are common therapeutic strategies among older patients. ${ }^{18,19}$

Patients with schizophrenia usually need lifelong treatment with antipsychotics. Relatively few clinical trials of antipsychotics agents, however, have been conducted solely in the elderly. Howanitz et al (1999) reported the results of an open-label trial comparing clozapine with chlorpromazine in 42 elderly subjects with schizophrenia. ${ }^{20}$ After 12 weeks, both agents led to improvements in the Positive and Negative Syndrome Scale (PANSS) and Clinical Global Improvement (CGI) Scale with adverse events similar between the two agents. A larger controlled study conducted in 117 patients with schizophrenia over age 60 compared olanzapine (5 to $20 \mathrm{mg}$ daily) with haloperidol (5 to $20 \mathrm{mg}$ daily) for six weeks. ${ }^{21}$ A greater improvement on the total PANSS score occurred in the olanzapine group compared with the haloperidol group. Jeste and Barak conducted an eight-week double-blind, multisite trial comparing olanzapine and risperidone in 175 elderly inpatients and outpatients with schizophrenia. ${ }^{22}$ Both treatments produced significant improvement on the PANSS total, positive and negative symptom scale scores. There was no significant difference in rates of extrapyramidal symptoms (EPS) between the two groups.

Since the elderly are at greater risk of developing tardive dyskinesia, this renders the management of their disorder more complicated. In addition, high levels of medical co-morbidity and the resulting polypharmacy increase the risk for deleterious drug interactions. As previously discussed, impaired cognition also complicates pharmacologic treatment and increases the risk of central nervous system (CNS) adverse events.

\section{Role of aripiprazole Aripiprazole}

Aripiprazole, a quinolone derivative, is a second-generation antipsychotic (SGA) approved by the FDA for treatment of schizophrenia; manic and mixed episodes associated with bipolar disorder (either as monotherapy or as an adjunct to lithium or valproate); maintenance treatment of bipolar I disorder; and as an adjunctive treatment for inadequately treated major depression. Unlike any other approved antipsychotic, it is a partial agonist at the $\mathrm{D}_{2}$ and $\mathrm{D}_{3}$ receptors. ${ }^{23}$ At the $\mathrm{D}_{2}$ receptor, it may function more as an antagonist in hyperdopaminergic states and as an agonist in hypodopaminergic states. Like other SGAs, it is also an antagonist at the $5-\mathrm{HT}_{2}$ receptor with strong affinity for the $5-\mathrm{HT}_{2 \mathrm{a}}$ and $5-\mathrm{HT}_{2 \mathrm{~b}}$ subtypes. In addition, it has partial agonist activity at the $5-\mathrm{HT}_{1 \mathrm{a}}$ receptor.

For schizophrenia, the recommended target dose range is 10-15 mg per day with a full dose range of 5-30 mg daily. Aripiprazole and its active metabolite exhibit extended elimination half-lives (ie, approximately 75 and 95 hours, respectively). In this regard, there is a risk of excessive 
accumulation, especially in the elderly, if the dose is escalated rapidly. Based on pharmacokinetic studies, the product labeling does not recommend any specific dose adjustments in the elderly. For example, a study examining single dose administration of aripiprazole in 60 individuals did not demonstrate any influence of age on its pharmocokinetics. ${ }^{24}$ Nearly $100 \%$ of both aripiprazole and its active metabolite, dehyro-aripiprazole, are bound to plasma protein. ${ }^{25}$ Thus, combining aripiprazole with other agents which are also highly protein bound may increase the free fraction of this antipsychotic to a level which may produce clinically relevant effects, particularly in the elderly. In this situation, a decrease in dose may be warranted. The drug is eliminated by hepatic pathways, namely the cytochome P450 (CYP) 3A4 and 2D6 enzyme systems. Thus, dosage may need adjustment when administered with 3A4 inhibitors (eg, ketoconazole) and inducers (eg, carbamazepine) or 2D6 inhibitors (eg, paroxetine, fluoxetine).

In adults, efficacy of this agent was demonstrated in several, double-blind, placebo-controlled trials for the acute treatment of schizophrenia. ${ }^{26,27}$ Onset of effect was noted as early as one-two weeks. A pooled post-hoc analysis of efficacy data from five short-term studies found that aripiprazole improved all five PANSS factor scores (positive, negative, disorganized thought, depression/anxiety, and hostility) from baseline and was comparable to both haloperidol and risperidone.$^{28}$ Longer-term maintenance trials lasting up to 52 weeks also support a role for aripiprazole in the management of chronic schizophrenia. ${ }^{29,30}$ Patients in these trials, however, were primarily under the age of 65 .

\section{Aripiprazole in the elderly}

While trials of aripiprazole for schizophrenia primarily involved younger subjects, one 26-week maintenance trial of aripiprazole did include patients aged up to 77 years. The mean age of all participants was 41 years and the precise number of those older than 65 years was not reported. In this study, 310 patients with chronic schizophrenia were randomized to aripiprazole $15 \mathrm{mg}$ daily or placebo. The primary outcome measure was time to relapse, which was significantly longer in the active treatment group compared with placebo $(P<0.001) .{ }^{29}$ Aripiprazole also produced significantly greater reductions in the PANSS total and PANSS positive symptom scale scores $(P<0.01)$. Whether aripiprazole had a differential effect in older subjects was not discussed.

A 52-week, open-label continuation study was conducted as an extension of this maintenance trial. ${ }^{31}$ Subjects from the original study were eligible for the extension phase if they were stable after completing the acute phase or met the original protocol criteria for relapse after completing a minimum of two weeks, double-blind treatment. Participants were then randomized to either aripiprazole (15-30 mg daily) or olanzapine (10-20 mg daily). Both treatment groups achieved similar improvements based on change in the PANSS total score. Compared to aripiprazole, however, greater weight gain occurred in the olanzapine-treated group. Aripiprazole treatment also resulted in a more favorable fasting glucose and lipid profiles. Age was not reported to be a moderating factor in this analysis.

A randomized, 14-week, open-label trial examined two different switching strategies. ${ }^{32}$ The mean age of the 48 participants in the two treatment groups was $54.5( \pm 15.0)$ and $53.0( \pm 17.7)$ years. Subjects aged over 65 years were also included, although the exact number was not reported. Men and women with schizophrenia treated with other antipsychotics were either: (a) treated adjunctively with aripiprazole for four weeks before tapering the other antipsychotic; or (b) initiated on adjunctive aripiprazole with simultaneous tapering of the other antipsychotic. Aripiprazole was initiated at $12 \mathrm{mg}$ daily and titrated up to $30 \mathrm{mg}$ as needed. Dosage of the previous antipsychotic was reduced by $25 \%$ on a biweekly basis. No differences were found between the groups with regard to the outcomes measured (ie, the Clinical Global Impression Scale - Schizophrenia Version, the Drug-Induced Extrapyramidal Symptoms Scale, and the Subjective Wellbeing Under Neuroleptics, Short Version, Japanese edition). The authors did not report age to be a modifying factor in their analysis.

In addition to these studies, the use of aripiprazole in late-life schizophrenia is also considered in case reports. For example, Madhusoodan et al described the use of aripiprazole in elderly patients with schizophrenia or schizoaffective disorder. ${ }^{33}$ This retrospective review identified ten patients between the ages of 62 and 86 years who were previously treated with first or second generation antipsychotics. Response was based on clinical observations and the CGI-I Scale. Seven of the ten responded, two had a partial response and one did not respond. Improvement was seen in both negative and positive symptoms. Of the seven who improved, four had pre-existing symptoms of EPS which subsequently resolved after starting aripiprazole. Another patient with severe tardive dyskinesia (TD) showed improvement in the abnormal movements. Four of the ten patients experienced postural hypotension, which resolved over time; six patients lost weight (average 5.2 pounds); and excessive sedation and QTc prolongation were not reported. 
The case of a 68 year-old man with paranoid schizophrenia and mild intellectual dysfunction was described by Shastri et al. ${ }^{34}$ This patient was previously treated with risperidone (4 mg daily), but experienced akathisia, tremors, and tardive dyskinesia. Two weeks after switching to aripiprazole, his EPS symptoms resolved and auditory hallucinations dissipated. By contrast, a 72-year-old woman with schizophrenia experienced worsening of her positive symptoms after switching to aripiprazole. ${ }^{35}$ Previously treated with haloperidol, this patient was initiated on aripiprazole ( $7.5 \mathrm{mg}$ daily) and titrated up to $15 \mathrm{mg}$ daily. Several months later she appeared more interactive and communicative, but her psychosis gradually worsened with increased delusions and aggressive behavior. Trifluoperazine was introduced and her psychotic symptoms resolved. When the trifluoperazine was stopped several months later (while the aripiprazole was continued), the symptoms recurred. As a result, the patient was ultimately restabilized on trifluoperazine monotherapy.

\section{Issues of tolerability and patient acceptance}

SGAs, including aripiprazole, are usually associated with a lower risk of EPS and TD compared with FGAs. We emphasize, however, that the elderly are generally more susceptible to developing these complications when exposed to antipsychotics. These adverse events can be socially disabling and compromise treatment adherence. While not totally avoidable, lower risk of TD in older populations on SGAs may translate to relatively greater tolerability and medication adherence.

The adverse events seen most commonly (ie, occurring in $\geq 5 \%$ of patients and at least twice that for placebo) in adults taking aripiprazole during clinical trials included akathisia, sedation, restlessness, tremor, EPS, fatigue, constipation, and nausea. A meta-analysis of five acute schizophrenia trials lasting 4 to 6 weeks, however, concluded that aripiprazole was generally well tolerated..$^{36}$ The most common treatmentemergent adverse effects were headache, anxiety, insomnia, agitation, and akathisia. The adverse event profile in longerterm trials was similar. ${ }^{29,30}$ EPS, as measured by the Simpson Angus Scale (SAS), the Barnes-Akathisia Scale (BAS) and the Abnormal Involuntary Movement Scale (AIMS), occurred at a similar incidence and severity as placebo in this meta-analysis. Two trials, ${ }^{26,29}$ however, found a higher incidence of EPS in patients receiving aripiprazole compared with placebo. In studies with an active comparator, EPS-related adverse events occurred at a similar rate to olanzapine and risperidone $e^{25}$ and less than haloperidol. ${ }^{36}$
Because of its moderate affinity for the $\alpha_{2}$ adrenergic receptor, aripiprazole may produce comparatively less orthostasis, leading to greater tolerability. We note, however, that elderly patients often suffer from comorbid cardiovascular and cerebrovascular disorders; usually are taking medications (eg, antihypertensives) to manage these conditions; and thus may be at greater risk for complications associated with the anti- $\alpha$ adrenergic effects of agents such as aripiprazole. Compared with other SGAs, aripiprazole is associated with a relatively lower risk of metabolic complications such as weight gain, hyperlipidemia, and diabetes mellitus. ${ }^{37}$ The mean weight gain in short-term trials was less than $1 \mathrm{~kg} .{ }^{36}$ For all doses of aripiprazole, the mean increase in weight (ie, $0.71 \mathrm{~kg}$ ) was similar to haloperidol (ie, $0.56 \mathrm{~kg}$ ).

The FDA requires a box warning regarding the use of antipsychotics, including aripiprazole, in elderly patients with dementia-related psychosis. This is due to an increased incidence of mortality and cerebrovascular events with these agents compared with placebo. Therefore, antipsychotics, such as aripiprazole should be avoided in this population if possible. When necessary, starting doses should be with the lowest amount possible; titration should be slow with increments also at the lowest amount; the dose should be given in a divided schedule; and frequent reassessment conducted to minimize the duration of exposure.

Adverse event-related sedation is a concern for elderly patients as they may be prone to experience mental status changes. Excessive sedation may occur with polypharmacy, the expectable age-related decline in cognition, and alterations in drug metabolism. In this context, data from acute schizophrenia trials with aripiprazole in adults demonstrate rates of sedation (11\%) similar to placebo (8\%). The rate of somnolence was also similar to placebo and decreased over time. Again, these issues may be magnified in older patients with other forms of CNS compromise.

Antipsychotic medications are associated with prolongation of the QT interval. This is of particular concern in the elderly as this population is more likely to have co-morbid cardiovascular disease. As with sedation, data from the five short-term trials demonstrated a low risk of risk of QT prolongation in younger adults. ${ }^{38}$

Studies of aripiprazole for a variety of psychiatric disorders support the general safety of this agent in older individuals. For example, Copley et al conducted a retrospective analysis of 52 elderly subjects treated with aripiprazole in a university inpatient unit. ${ }^{38}$ The most common diagnoses included schizophrenia/schizoaffective disorder, bipolar disorder, major depressive disorder and Alzheimer's disease. All subjects were 
aged over 65 years: 18 (35\%) were aged 65-69 years; $13(25 \%)$ were aged $70-74$ years; 14 (27\%) were aged $75-79$ years, and $7(13 \%)$ were aged $>80$ years. The mean maximum daily dose of aripiprazole was $13.9( \pm 9.4) \mathrm{mg}$. Higher doses were used for schizophrenia or bipolar disorder compared with major depression. Nine patients had documented adverse events, the most common being 'agitation/activation'. EPS was reported in two patients; while confusion, fatigue and lightheadedness were reported in one patient each.

In a placebo-controlled trial of aripiprazole in 208 outpatients with Alzheimer's disease complicated by psychosis, ${ }^{39}$ the adverse events more commonly seen in the active vs placebo group were: accidental injury (8\%), somnolence $(8 \%)$, bronchitis (6\%), and EPS-related symptoms (5\%). In another placebo-controlled trial of 256 elderly subjects with Alzheimer's disease and psychosis, only somnolence occurred at a greater rate in the active treatment group (ie, $14 \%$ vs $4 \%$ in placebo). ${ }^{40}$ The somnolence was rated mild to moderate in intensity and was not associated with accidental injury. In both of these trials, however, there was an increased rate of cerebrovascular events including fatalities in the aripiprazole-treated patients. Twenty older adults with bipolar disorder received open-label aripiprazole for 12 weeks. ${ }^{41}$ While no patients discontinued due to adverse effects, the most common events were restlessness $(\mathrm{n}=3,15.8 \%)$; weight gain over $7 \%$ of baseline level $(\mathrm{n}=3$, $15.8 \%)$; and sedation $(\mathrm{n}=2,10.5 \%)$. Finally, a six-week augmentation study of aripiprazole was conducted in 20 older (ie, mean age $63( \pm 9.6)$ years) individuals with depression. ${ }^{42}$ The most common adverse effects included dry mouth (25\%), agitation/anxiety (20\%), and drowsiness (15\%).

\section{Conclusion}

As the US population continues to age, there will be an increasing need to prescribe antipsychotics for a variety of disorders, including schizophrenia. The limited evidence base to guide their optimal administration presents a challenge to clinicians. The available literature indicates that aripiprazole can be effective and generally well-tolerated. Important age-related factors, as well as the pharmacokinetics of aripiprazole (eg, longer elimination half-life), dictate the need for conservative dosing; the avoidance of polypharmacy when possible; careful monitoring for the development of adverse events and/or drug interactions; and more careful titration and tapering strategies.

\section{Disclosure}

Philip Janicak Grant/Reasearch: Otsuka, Neuronetics; Advisor/Consultant: Bristol Myers Squibb, Neuronetics,
Takeda; Speakers' Bureau: Astra Zeneca, Bristol Myers Squibb/Otsuka, Janssen, Neuronetics, Novartis. Jeffrey Rado Research/Grant: Otsuka, Neuronetics, Lilly Speakers Bureau: Lilly.

\section{References}

1. Rado J, Janicak PG. Schizophrenia. In: Rakel RE, Bope ET, editors. Conn's Current Therapy 2009. Philadelphia, PA: Saunders Elsevier; 2009.

2. Rabins PV, Black B, German P, et al. The prevalence of psychiatric disorders in elderly residents of public housing. J Gerontol A Biol Sci Med Sci. 1996;51(6):M319-M324.

3. Jeste DV, Symonds LL, Harris MJ, Paulsen JS, Palmer BW, Heaton RK. Non-dementia non-praecox dementia praecox? Late-onset schizophrenia. Am J Geriatr Psychiatry. 1997;5:302-317.

4. Evans JD, Negron AE, Palmer BQ, Paulsen JS, Heaton RK, Jeste DV. Cognitive deficits and psychopathology in institutionalized versus community-dwelling elderly. J Geriatr Psychiatry Neurol. 1999; 12:11-15.

5. Cuffel BJ, Jeste DV, Halpain M, Pratt C, Tarke H, Patterson TL. Treatment costs and use of community mental health services for schizophrenia by age-cohorts. Am J Psychiatry. 1996;153:870-876.

6. Zisook S, McAdams LA, Kuck J, et al. Depressive symptoms in schizophrenia. Am J Psychiatry. 1999;156:1736-1743.

7. Jin H, Zisook S, Palmer B, Patterson TL, Heaton RK, Jeste D. Association of depressive symptoms with worse functioning in schizophrenia: A study of older outpatients. J Clin Psychiatry. 2001;62:797-803.

8. Osby U, Correia N, Brandt L, Ekbom A, Sparén P. Mortality and causes of death in schizophrenia in Stockholm County, Sweden. Schizophr Res. 2000;45:21-28.

9. Meeks S, Woodruff-Borden J. Anxiety: Comordidity and impact in severe mental illness. J Clin Geropsychol. 1996;2:141-152.

10. Harvey PD, Friedman JI. Cognitive functioning in late-life schizophrenia. In CI Cohen (editor). Schizophrenia into later life. Arlington, 1999: American Psychiatric Publishing.

11. Kurtz MM. Neurocognitive impairment across the lifespan in schizophrenia: an update. Schizophr Res. 2005;74:15-26.

12. Cohen CI. Studies of the outcome of schizophrenia in later life. Psychiatr Serv. 1995;46:877-879.

13. Bartels SJ, Muser KT, Miles KM. Functional impairments in elderly patients with schizophrenia and major affective disorders living in the community: social skills, living skills and behaviour problems. Behav Ther. 1997;28:43-63.

14. Klapow J, Evans J, Patterson TL, Heaton RK, Koch WL, Jeste DV. Direct assessment of functional status in older patients with schizophrenia. Am J Psychiatry. 1997;154:1022-1024.

15. Patterson TL, Klapow JC, Eastham JH, et al. Correlates of functional status in older outpatients. Psychiatry Res. 1998;80:41-52.

16. Gupta S, Steinmeyer CH, Lockwood K, Lentz B, Schultz K. Comparison of older patients with bipolar disorder and schizophrenia/schizoaffective disorders. Am J Geriatr Psychiatry. 2007;15:627-633.

17. Berry K, Barrowclough C. The needs of older adults with schizophrenia: Implication for psychological interventions. Clin Psychol Rev. 2009;29:68-76.

18. Cohen CI. Age-related correlations in patient symptom management strategies in schizophrenia: An exploratory study. Int J Geriatr Psychiatry. 1993;8:211-213.

19. Salano N, Krauss Whitbourne S. Coping with schizophrenia: Patterns in later adulthood. Int J Aging Hum Dev. 2001;53:1-10.

20. Howanitz E, Pardo M, Smelson DA, Engelhart C, Eisenstein N, Losonczy MF. The efficacy and safety of clozapine versus chlorpromazine in geriatric schizophrenia. J Clin Psychiatry. 1999;60(1):41-44.

21. Kennedy JS, Jeste D, Kaiser CJ. Olanzapine vs haloperidol in geriatric schizophrenia: analysis of data from a double-blind controlled trial. Int J Geriatr Psychiatry. 2003;18:1013-1020. 
22. Jeste DV, Barak Y. International multisite double-blind trial of the atypical antipsychotics risperidone and olanzapine in 175 elderly patients with chronic schizophrenia. Am J Geriatr Psychiatry. 2003;11:638-647.

23. Janicak PG, Davis JM, Preskorn SH, Ayd FJ Jr. Principles and Practice of Psychopharmacotherapy. 4th Ed. Philadelphia, PA: Lippincott Williams \& Wilkins; 2006:81-181

24. Mallikaarjin S, Ali MW, Salazar DE, et al. The effects of age and gender on the pharmacokinetics of aripiprazole. Clin Pharmacol Ther. 2002;71(2):66.

25. Harrison TS, Perry CM. Aripiprazole: A review of its use in schizophrenia and schizoaffective disorder. Drugs. 2004;64(15):1715-1736.

26. Potkin SG, Saha AR, Kujawa MJ, et al. Aripiprazole, an antipsychotic with a novel mechanism of action, and risperidone vs placebo in patients with schizophrenia and schizoaffective disorder. Arch Gen Psychiatry. 2003;60(7):681-690.

27. Kane JM, Carson WH, Saha AR, et al. Efficacy and safey of aripiprazole and haloperidol versus placebo in patients with schiaophrenia and schizoaffective disorder. J Clin Psychiatry. 2002;63(9):763-771.

28. Janicak PG, Glick ID, Marder SR, et al. The acute efficacy of aripiprazole across the symptom spectrum of schizophrenia: a pooled post hoc analysis from 5 short term studies. J Clin Psychiatry. 2009;70(1):25-35.

29. Pigott TA, Carson WH, Saha AR, et al. Aripiprazole for the prevention of relapse in stabilized patients with chronic schizophrenia: a placebocontrolled 26 week study. J Clin Psychiatry. 2003;64(9):1048-1056.

30. Kasper S, Lerman MN, McQuade RD, et al. Efficacy and safety of aripiprazole vs haloperidol for long-term maintenance treatment following acute relapse of schizophrenia. Int J Neuropsychopharmacol. $2003 ; 6: 325-337$.

31. Wlodzimiewrz CK, Marcus RN, Tobeyns A, Nyilas M, McQuade RD. Effectiveness of long-term aripiprazole therapy in patients with acutely relapsing or chronic, stable schizophrenia: a 52-week, open-label comparison with olanzapine. Psychopharmaology. 2006;189:259-266.

32. Takeuchi H, Suzuki T, Uchida H, et al. A randomized, open-label comparison of 2 switching strategies to aripiprazole treatment in patients with schizophrenia. J Clin Psychopharmacol. 2008;28:540-543.
33. Madhusoodan S, Brenner R, Gupta S, Reddy H, Bogunovic O. Clinical experience with aripiprazole treatment in ten elderly patients with schizophrenia or schizoaffective disorder: retrospective case studies. CNS Spectrums. 2004;9(11)862-867.

34. Shastri M, Alla L, Sabaratnam M. Aripiprazole use in individuals with intellectual disability and psychotic or behavioural disorders: a case series. J Psychopharmacol. 2006;20(6):863-867.

35. Ponde MP, Novaes CM. Aripiprazole worsening positive symptoms and meantime reducing negative symptoms in a patient with paranoid schizophrenia. Rev Bras Psiquiatr. 2007;29(1):86-95.

36. Marder SR, McQuade RD, Stock E, et al. Aripiprazole in the treatment of schizophrenia: safety and tolerability in short-term, placebo-controlled trials. Schizophr Res. 2003;61:123-136.

37. American Diabetes Association, American Psychiatric Association, American Association of Clinical Endocrinologists, North American Association for the Study of Obesity. Consensus development conference on antipsychotic drugs and obesity and diabetes. Diabetes Care. 2004;27(2):596-601.

38. Copley K, Scipio TM, Ruby C, Lenze EJ, Fabian T. Aripiprazole prescribing patterns and side effects in elderly psychiatric inpatients. $J$ Psychiatr Pract. 2009;15:150-153.

39. De Deyn P, Jeste DV, Swanink R, et al. Aripiprazole for the treatment of psychosis in patients with Alzheimer's disease: a randomized, placebocontrolled study. J Clin Psychopharmacol. 2005;25:463-467.

40. Streim JE, Porsteinsson AP, Breder CD, et al. A randomized, doubleblind, placebo-controlled study of aripiprazole for the treatment of psychosis in nursing home patients with Alzheimer disease. Am J Geriatr Psychiatry. 2008;16(7):537-550.

41. Sajatovic M, Coconcea N, Ignacio RV, et al. Aripiprazole therapy in 20 older adults with bipolar disorder: a 12-week, open-label trial. J Clin Psychiatry. 2008;69(10):41-46.

42. Rutherford B, Sneed K, Miyazaki M, et al. An open trial of aripiprazole augmentation for SSRI non-remitters with late-life depression. Int J Geriatr Psychiatry. 2007;22:986-991.
Clinical Interventions in Aging

\section{Publish your work in this journal}

Clinical Interventions in Aging is an international, peer-reviewed journal focusing on evidence-based reports on the value or lack thereof of treatments intended to prevent or delay the onset of maladaptive correlates of aging in human beings. This journal is indexed on PubMed Central, MedLine, the American Chemical Society's 'Chemical

\section{Dovepress}

Abstracts Service' (CAS), Scopus and the Elsevier Bibliographic databases. The manuscript management system is completely online and includes a very quick and fair peer-review system, which is all easy to use. Visit http://www.dovepress.com/testimonials.php to read real quotes from published authors. 